\title{
SOLUBILITY DATA OF SEVERAL SOLVENTS IN ACETIC ACID SEPARATION PROCESS
}

\author{
K.Sofiya ${ }^{1}$, B.Karunanithi ${ }^{2}$, R.Thilakavathi ${ }^{3}$
}

\begin{abstract}
The selection of solvents for acetic acid separation process was investigated with several solvents namely Butyl Butyrate, Benzene, Diisopropyl ether (DIPE), Methyl Iso Butyl Ketone (MIBK), and Ethyl Acetate. The suitable solvent for extracting acetic acid was determined experimentally by cloud point method. As the result of experimental data the hierarchy of selecting the order of the solvent based on two-phase region was given as, Ethyl Acetate > MIBK >DIPE > Benzene > Butyl Butyrate. The solubility data of several solvents were reported and compared.
\end{abstract}

Key words: Solubility data, cloud point method, binodal curve, solvent selection

\section{INTRODUCTION}

Aqueous acetic acid is produced during the process of many chemical reactions. The Separation of Acetic acid by aqueous solutions by simple rectification is difficult because it requires a column with many numbers of stages and a high reflux ratio, the process become more expensive. The selection of process depends on the acetic acid feed concentration, the feed containing $50 \%$ to $70 \%$ the extractive distillation is used, below its $50 \%$ the solvent extraction is preferred one. Several researchers studied with different solvents, one of the desired characteristic are gap in the two phase region should be more. Increase in feed concentration required addition of solvent. In order to find out the ability of solvent for the separation of acetic acid from aqueous solution, mutual solubility data were obtained using organic solvents such as Butyl butyrate, Benzene, Diisopropyl ether ,Methyl Iso Butyl Ketone, Ethyl Acetate by cloud-point method.

\section{MATERIAL AND METHODS}

\section{MATERIALS}

The chemicals acetic acid (99.9\%) obtained from Qualigens fine chemicals and solvents obtained from Fisher scientific India pvt Ltd, were used without further purification. The purity of these materials was checked by gas chromatography. Distilled water was prepared in our laboratory and used throughout all experiments.

The binodal curves (mutual solubility curves) for acetic acid distributed between water and an organic solvent were obtained by titrating known mixtures of two components (water and solvents) with the third component acetic acid to the point of first appearance of permanent turbidity. The different proportion of water and Acetic acid was taken in to the flask; solvent is added drop by drop until the transition change from homogeneity to heterogenic phase was observed. The water side data were determined by taking different proportion of Acetic acid and solvent in to the flask and water is added drop by drop until the turbidity was obtained. The experiments were repeated two times in order to get accuracy. Thus the mutual solubility curve for acetic acid-water-solvents system was obtained. The mole fraction of three component system is obtained by the weight of the individual sample and from the material balance equation.

${ }^{1}$ Department of Chemical Engineering SRM University, Chennai, Tamil Nadu, India

${ }^{2}$ Department of Chemical Engineering SRM University, Chennai, Tamil Nadu, India

${ }^{3}$ Department of Chemical Engineering SRM University, Chennai, Tamil Nadu, India 


\section{RESULTS AND DISCUSSION}

The solubility data for the system water + Acetic acid + Solvents (Butyl Butyrate, Benzene, MIBK, DIPE, and Ethyl Acetate) were reported in the following table 1 in terms of mole fraction. The individual five solvents data were reported separately.

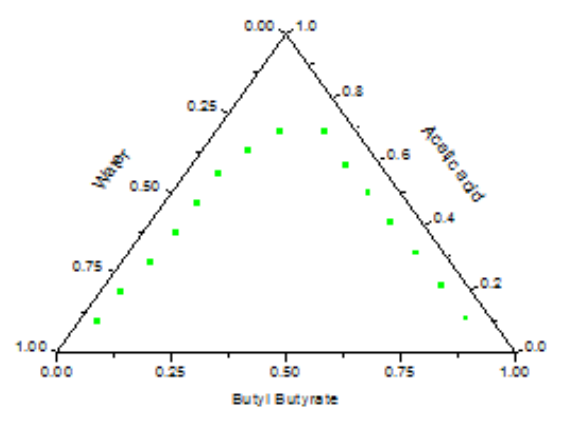

(i)

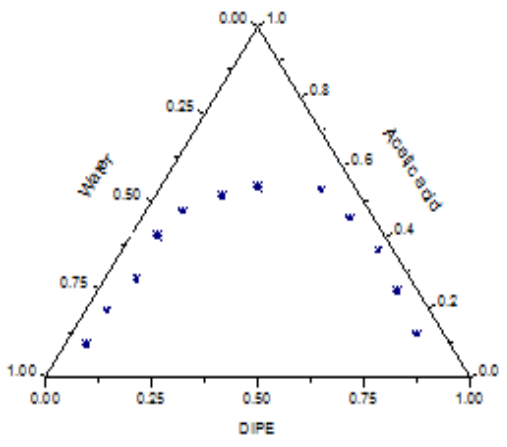

(iii)

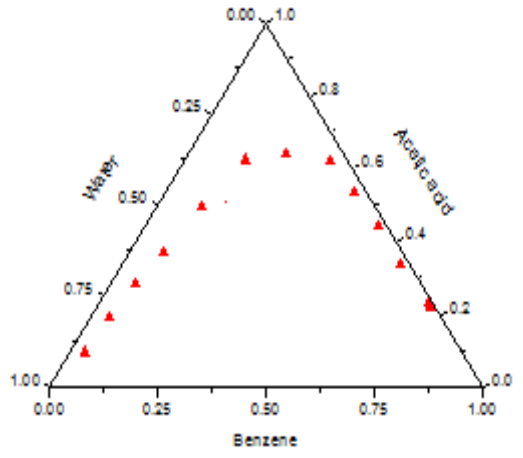

(ii)

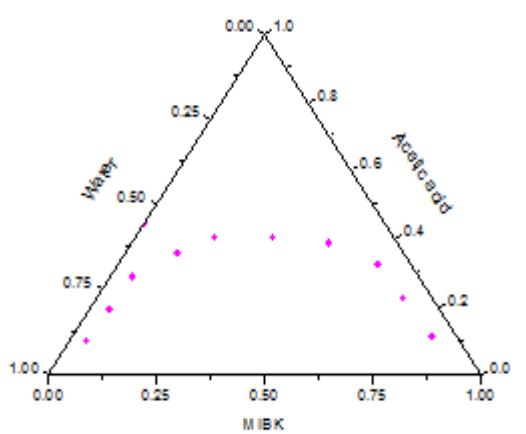

(iv)

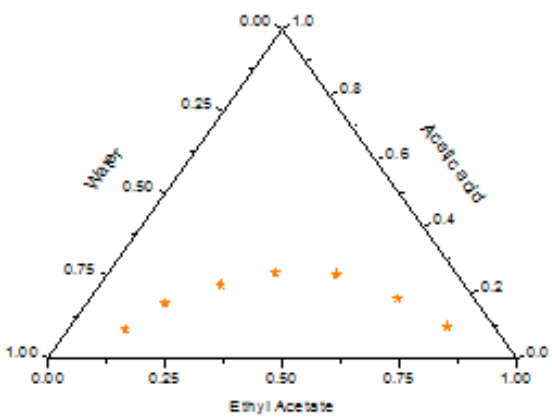

(v)

Figure.1. Solubility curve for water + Acetic acid + Solvents ((i) Butyl Butyrate, (ii) Benzene, (iii) Diisopropyl ether, (iv) Methyl Iso Butyl Ketone, (v) Ethyl Acetate) 
Table-1: Solubility data for the system water + Acetic acid + Solvents ( (i) Butyl Butyrate, (ii)Benzene, (iii) Diisopropyl, (iv) Methyl Iso Butyl Ketone, (v) Ethyl Acetate )

\begin{tabular}{cccccc}
\hline \multicolumn{6}{c}{ Water + Acetic acid + Butyl Butyrate } \\
\hline A(water) & B(BB) & C(AA) & A(Water) & B(BB) & C(AA) \\
0.8617 & 0.0416 & 0.0967 & 0.0538 & 0.8378 & 0.1084 \\
0.7652 & 0.0416 & 0.1932 & 0.0549 & 0.7335 & 0.2116 \\
0.6554 & 0.0609 & 0.2837 & 0.0619 & 0.6257 & 0.3124 \\
0.5545 & 0.0722 & 0.3733 & 0.0694 & 0.5258 & 0.4084 \\
0.4598 & 0.0758 & 0.4644 & 0.0698 & 0.4285 & 0.5017 \\
0.3675 & 0.0758 & 0.5567 & 0.0776 & 0.3357 & 0.5867 \\
0.2679 & 0.1007 & 0.6314 & 0.1984 & 0.2102 & 0.5914 \\
0.1705 & 0.1406 & 0.6889 & 0.2574 & 0.1312 & 0.6114 \\
0.0693 & 0.2395 & 0.6912 & 0.3256 & 0.0534 & 0.621 \\
\hline
\end{tabular}

\begin{tabular}{cccccc}
\hline \multicolumn{6}{c}{ Water + Acetic acid + Benzene } \\
\hline $\mathrm{A}$ (water) & $\mathrm{B}($ Ben) & $\mathrm{C}(\mathrm{AA})$ & $\mathrm{A}($ Water $)$ & $\mathrm{B}(\mathrm{Ben})$ & $\mathrm{C}(\mathrm{AA})$ \\
0.8707 & 0.0316 & 0.0977 & 0.5024 & 0.041 & 0.4566 \\
0.7672 & 0.0392 & 0.1936 & 0.401 & 0.1008 & 0.4982 \\
0.6622 & 0.0537 & 0.2841 & 0.1361 & 0.2226 & 0.6413 \\
0.5527 & 0.0753 & 0.372 & 0.0412 & 0.3362 & 0.6226 \\
0.4434 & 0.1088 & 0.4478 & 0.0319 & 0.4332 & 0.5349 \\
0.3421 & 0.1398 & 0.5181 & 0.0219 & 0.5365 & 0.4416 \\
0.2345 & 0.1397 & 0.6258 & 0.0205 & 0.6393 & 0.3402 \\
0.1708 & 0.1396 & 0.6896 & 0.0116 & 0.7553 & 0.2331 \\
0.1513 & 0.0842 & 0.7645 & 0.0102 & 0.7664 & 0.2234 \\
\hline
\end{tabular}

\begin{tabular}{cccccc}
\hline \multicolumn{5}{c}{ Water + Acetic acid + MIBK } \\
\hline A(water) & B(MIBK) & C(AA) & A(Water) & B(MIBK) & C(AA) \\
0.8645 & 0.0385 & 0.097 & 0.0589 & 0.866 & 0.1159 \\
0.7619 & 0.0458 & 0.1923 & 0.0666 & 0.7095 & 0.2239 \\
0.661 & 0.0529 & 0.2861 & 0.0751 & 0.6002 & 0.3247 \\
0.5244 & 0.1225 & 0.3531 & 0.1563 & 0.4554 & 0.3833 \\
0.3773 & 0.2416 & 0.3811 & 0.279 & 0.3187 & 0.4023 \\
0.298 & 0.2505 & 0.4515 & 0.4698 & 0.1832 & 0.347 \\
0.1697 & 0.4302 & 0.4001 & 0.6451 & 0.0899 & 0.265 \\
0.2202 & 0 & 0.8898 & 0.64 & 0.0595 & 0.3005 \\
0.0991 & 0 & 0.9008 & 0.0001 & 0.0808 & 0.9191 \\
& & & & \\
\hline
\end{tabular}

Water + Acetic acid + DIPE

\begin{tabular}{cccccc}
\hline $\mathrm{A}($ water $)$ & $\mathrm{B}(\mathrm{DIPE})$ & $\mathrm{C}(\mathrm{AA})$ & $\mathrm{A}($ Water $)$ & $\mathrm{B}(\mathrm{DIPE})$ & $\mathrm{C}(\mathrm{AA})$ \\
0.8559 & 0.0481 & 0.096 & 0.5048 & 0.0365 & 0.4587 \\
0.7601 & 0.0481 & 0.1918 & 0.4405 & 0.085 & 0.4745 \\
\hline
\end{tabular}




\begin{tabular}{cccccc}
\hline 0.6467 & 0.0735 & 0.2798 & 0.3276 & 0.158 & 0.5144 \\
0.5892 & 0.0142 & 0.3966 & 0.2184 & 0.2527 & 0.5289 \\
0.4378 & 0.1203 & 0.4419 & 0.0846 & 0.3822 & 0.5332 \\
0.3123 & 0.2147 & 0.473 & 0.0564 & 0.4889 & 0.4547 \\
0.2302 & 0.2276 & 0.5422 & 0.0358 & 0.6034 & 0.3608 \\
0.1501 & 0.2442 & 0.6057 & 0.0488 & 0.7053 & 0.2459 \\
0.0991 & 0.0001 & 0.9008 & 0.0624 & 0.8118 & 0.1258 \\
\hline & Water + Acetic acid + Ethyl Acetate & \\
\hline A(water) & B(EA) & C(AA) & A(Water) & B(EA) & C(AA) \\
0.7923 & 0.1189 & 0.0888 & 0.0001 & 0.0901 & 0.9098 \\
0.6666 & 0.1651 & 0.1683 & 0.0001 & 0.1823 & 0.8176 \\
0.5204 & 0.2544 & 0.2252 & 0.0001 & 0.2765 & 0.7234 \\
0.3863 & 0.3537 & 0.26 & 0.0001 & 0.3729 & 0.627 \\
0.2564 & 0.4848 & 0.2588 & 0 & 0.4715 & 0.5285 \\
0.3976 & 0.0001 & 0.6023 & 0.5015 & 0.2853 & 0.2132 \\
0.2979 & 0.0001 & 0.702 & 0.2613 & 0.499 & 0.2397 \\
0.1984 & 0.0001 & 0.8015 & 0.1633 & 0.6536 & 0.1831 \\
0.0991 & 0.0001 & 0.9008 & 0.0989 & 0.8013 & 0.0998 \\
\hline & & & & & \\
\hline
\end{tabular}

The shapes of the binodal curve for different solvents are shown in Fig 1. The area under the curve indicates the possibility of separation by these solvents. The heterogeneity area is very high for the solvent Butyl butyrate; it indicates the solvent can be used for higher feed concentration also. Ethyl acetate can be used for the lower feed concentration, if increase in the feed concentration this solvent fails to give results. Next to ethyl acetate the MIBK may be used as an effective solvent. The Benzene and DIPE can be used for high concentration of feed.

\section{IV.CONCLUSION}

The solubility data and binodal curve for the system water + acetic acid + Solvents (Butyl Butyrate, Benzene, Diisopropyl ether (DIPE), Methyl Iso Butyl Ketone (MIBK), and Ethyl Acetate) were determined at room temperature. The separation of acetic acid is possible by all the mentioned solvents; based on feed concentration the solvent can be preferred. The solvent preference based on the two phase region were given as Ethyl Acetate > MIBK $>$ DIPE > Benzene > Butyl Butyrate. This can be used as basic information for selection of solvent in acetic acid manufacturing process.

\section{REFERENCES}

[1] De Dietrich process, Recovery of Acetic acid by Liquid-Liquid extraction process, (www.dedietrich.com)

[2] D. Ozmen (2010) Liquid + liquid equilibria for the quaternary systems of (water + acetic acid + mixed solvent) at 298.2K and atmospheric pressure, Fluid Phase Equilibria, 293-297.

[3] E. Ince (2006) (Liquid + liquid) equilibria of the (water + acetic acid + dibasic esters mixture) system, science direct, J. Chem. Thermodynamics ,1669-1674.

[4] A.Singh, (2006). Recovery of acetic acid from aqueous solutions by reactive distillation. Ind. Eng. Chem. Res. Volume 45, pages 2017-2025.

[5] S.Haque, Separation of acetic acid from aqueous solution using various organic Solvents, Journal of Science and Technology, vol $5,2013$. 